poor correlation between EMG and nerve conduction studies and outcome in infants with obstetric brachial palsy. Surgery was considered in infants with OBP when no spontaneous motor recovery was clinically evident after 3 to 4 months. See Progress in Pediatric Neurology III, PNB Publ, 1997;pp357-359, for further comment on outcome of OBP following conservative management, and interpretation of EMG fibrillation potentials in newborns.

Outcome in OBP with and without surgery. Investigators at the Department of Neuropediatrics, Karolinska Hospital, Stockholm, examined the functional outcome at age 5 years of 247 children with OBP, with and without microsurgical reconstruction. In the operated group, improved shoulder range of movement in C5-6 palsies was the only benefit, compared to non-operated patients, and outcome was not correlated with the timing of operation, before or after age 6 months. A decrease in grip and bimanual function in C5-6 palsies was unexpected. Those with widespread C5-T1 lesions had the most root avulsions and the poorest hand function. Nerve reconstruction in the majority of infants with upper OBP lesions should be delayed until after 6 to 9 months. (Strombeck C, Krumlinde-Sundholm L, Forrsberg H. Dev Med Child Neurol March 2000;42:148157).

\title{
CONGENITAL MYOPATHY WITH APOPTOTIC CHANGES
}

A case of congenital myopathy with myonuclear changes consistent with apoptotic degeneration in a 4-year-old girl is reported from the National Institute of Neuroscience, Tokyo, Japan. She was hypotonic at birth and psychomotor development was markedly delayed. Brain MRI was normal. DNA fragmentation in myonuclei was demonstrated by the TUNEL method and supported by ultrastuctural characteristics and immunochemistry. (Ikezoe K, Yan C, Momoi T et al. A novel congenital myopathy with apoptotic changes. Ann Neurol April 2000;47:531-536). (Respond: Dr Ikezoe, Department of Ultrastructural Research, National Institute of Neuroscience, National Center of Neurology and Psychiatry, Tokyo 187-8502, Japan).

COMMENT. The authors add a new type of structural abnormality associated with congenital myopathy. Other types include central core disease, nemaline myopathy, myotubular myopathy, and congenital fiber-type disproportion.

\section{HIGH-DOSE IV IMMUNOGLOBULIN IN JUVENILE MYASTHENIA}

Ten children (median age, 13 years; range, 3-18 yrs) with juvenile myasthenia gravis were treated with high-dose intravenous immunoglobulin (2 $\mathrm{gm} / \mathrm{kg}$ body $\mathrm{wt}$ ) and prospectively evaluated for 5 years at the Department of Neurology, Wayne State University, Children's Hospital of Michigan, Detroit, MI. Improvement in functional strength occurred initially in 8 patients, but the response decreased after multiple monthly treatments. No correlation was noted between clinical response and a decrease in anti-AChR antibody levels measured in 3 patients. One child developed hypotension during the infusion and treatment was discontinued. Six patients complained of headache. (Selcen D, Dabrowski ER, Michon AM, Nigro MA. High-dose intravenous immunoglobulin therapy in juvenile myasthenia gravis. Pediatr Neurol 2000;22:40-43). (Respond: Dr Nigro, 28595 Orchard Lake Rd, Farmington Hills, MI 48334).

COMMENT. High-dose IV immunoglobulin may be of benefit in juvenile myasthenia gravis as a short-term therapy, at times of myasthenic crisis, and in preparation for surgery. 